\title{
Reversed Halo Sign: A Systematic Review
}

\author{
Venkata N Maturu MD and Ritesh Agarwal MD DM
}

\begin{abstract}
A reversed halo sign (RHS) is defined as the presence of a focal ring-shaped area of ground-glass opacity within a peripheral rim of consolidation. Although originally described in patients with cryptogenic organizing pneumonia, it has been described with several other noninfectious and infectious diseases, including fungal infections. Thus, it is imperative that a proper diagnosis be established before initiating treatment. In this article, we systematically review the literature (PubMed and Embase) for the associations of the RHS. We have also proposed a diagnostic algorithm for an approach to a patient with an RHS. Key words: reversed halo sign; RHS; computed tomography; HRCT; MDCT; Aspergillus; mucormycosis. [Respir Care 2014;59(9):1440-1449. () 2014 Daedalus Enterprises]
\end{abstract}

\section{Introduction}

The presence of central annular ground-glass opacity surrounded by a peripheral rim of consolidation, the socalled reversed halo sign (RHS), was first described in patients with cryptogenic organizing pneumonia ${ }^{1}$ and was considered fairly specific for this disease. ${ }^{2}$ Subsequently, several case reports and case series have reported the occurrence of the RHS in several other diseases (both infectious and noninfectious), thereby questioning the specificity of this sign. In this article, we systematically review the literature for the association of the RHS with various disorders. Furthermore, we also provide an algorithmic approach for a patient presenting with an RHS.

\section{Methods}

We first searched the PubMed and Embase databases for any systematic review reporting the association of the

\footnotetext{
The authors are affiliated with the Department of Pulmonary Medicine, Postgraduate Institute of Medical Education and Research, Chandigarh, India.
}

The authors have disclosed no conflicts of interest.

Correspondence: Ritesh Agarwal MD DM, Department of Pulmonary Medicine, Postgraduate Institute of Medical Education and Research, Chandigarh 160012, India. E-mail: riteshpgi@gmail.com, agarwal. ritesh@pgimer.edu.in.

DOI: $10.4187 /$ respcare.03020
RHS with various diseases. Only narrative reviews were found. We then independently searched the PubMed and Embase databases (January 1993 to November 2013) using the following free text terms: "reversed halo sign" OR "reverse halo sign" OR "atoll sign" OR "fairy ring sign" without any language restriction (Fig. 1). We included studies (case reports and original articles) describing the association of the RHS with various diseases. We excluded editorials and reviews. Any disagreement was resolved by discussion between the authors. The database created from the electronic searches was compiled in a reference manager package (EndNote X7, Thomson Reuters, Philadelphia, Pennsylvania), and all duplicate citations were eliminated. The citations were first screened by both authors to capture relevant studies. The full text of each citation was then obtained and reviewed in detail.

Data were recorded on a standard data extraction form. The following items were extracted: (1) publication details (title, authors, and other citation details), including country where the study was conducted; (2) patient demographics (age, sex, and immune status of the patient); and (3) modality used for establishing the diagnosis.

An institutional review board clearance was not required for this study, as this was a systematic review of published studies.

\section{Results}

Our initial database search yielded 94 citations, of which 58 case reports or case series (209 patients with an RHS) were included in the final review (Table 1). ${ }^{1-58}$ The RHS 


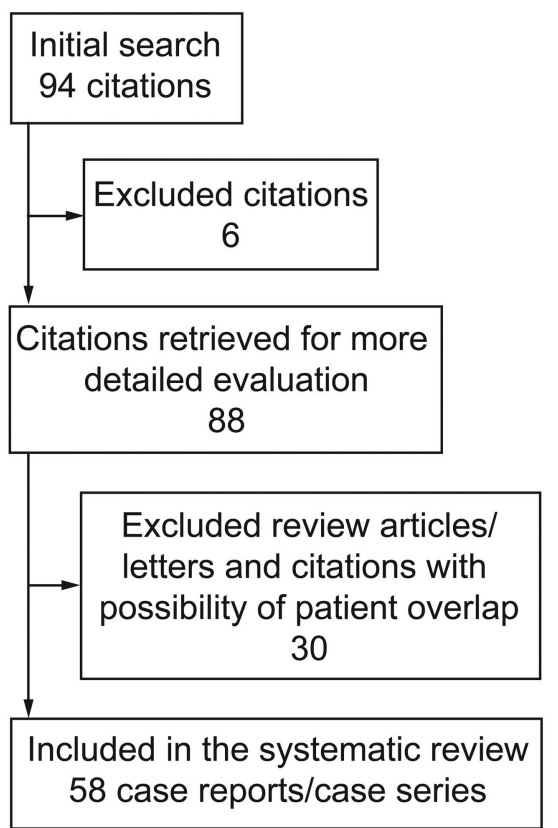

Fig. 1. Citation selection process for systematic review.

has been demonstrated to be present in several diseases, infectious as well as noninfectious (Table 2). The largest case series was published by Marchiori et $\mathrm{al}^{46}$ and included 79 patients.

\section{Infectious Diseases}

The RHS is most commonly associated with invasive fungal infections, most commonly with mucormycosis (see Table 2). It has not been described in candidiasis or fusariosis. All the case reports of invasive fungal infections with an RHS are in immunocompromised hosts (hematologic malignancies, diabetes mellitus, and post-chemotherapy state). The RHS has also been described in endemic infections such as paracoccidioidomycosis and tuberculosis. In invasive fungal infection complicating immunosuppressed individuals, the sign appears as one or more large lesions, whereas in endemic mycoses, the lesions are bilateral and asymmetric, associated with ground-glass opacities, centrilobular nodules, or areas of consolidation. ${ }^{8,41}$ Other infections where it is uncommonly seen are histoplasmosis, cryptococcosis, influenza, psittacosis, Pneumocystis, and Legionella pneumonia. In patients with pneumococcal pneumonia, the RHS has been seen in the resolution phase and thus represents a post-infectious organizing pneumonia. ${ }^{33}$

\section{Noninfectious Diseases}

The RHS was first described in cryptogenic organizing pneumonia, and this sign is most commonly associated with this condition. The RHS has been described in organizing pneumonia secondary to various causes (see Table 1). Other noninfectious diseases associated with the RHS are sarcoidosis, vasculitis, and a cellular variant of nonspecific interstitial pneumonia. Another important condition associated with the RHS is pulmonary thromboembolism, ${ }^{46,49}$ where the diagnosis would be based on clinicoradiologic grounds. There are also case reports of association with other diseases such as lipoid pneumonia, lymphomatoid granulomatosis, lymphocytic interstitial pneumonia, tuberous sclerosis complex, hypersensitivity pneumonia, and bronchoalveolar carcinoma.

\section{Histopathologic Correlation of the RHS}

The first pathologic description of the RHS was given by Voloudaki et $\mathrm{al}^{1}$ in cryptogenic organizing pneumonia. The central ground-glass opacity was due to alveolar septal inflammation with intact alveolar air spaces. The denser rim was due to inflammation/granulation tissue within the air space itself. A similar pathologic description has also been provided in other reports. ${ }^{6,8,54} \mathrm{In}$ all the aforementioned cases, the central ground-glass area had only alveolar septal inflammation, whereas the denser rim was composed of intra-alveolar infiltrate. However, in invasive fungal infections, the RHS is due to infarct, with greater hemorrhage at the periphery than in the center. ${ }^{20}$ The central infarct may show multiple levels of pulmonary arteries and veins extensively occluded by thrombi containing numerous Zygomycetes hyphae. In the peripheral ring, inflammation, massive hemorrhage, and fibrinous exudates were noted. ${ }^{45}$ In a patient with tumor emboli, the RHS lesion at autopsy was composed of central necrotic islands surrounded by a peripheral ring-like hemorrhagic band. The pulmonary vasculature and lymphatics near the hemorrhagic band were occluded by tumor emboli. ${ }^{52}$ In lymphomatoid granulomatosis, the central ground-glass opacity is due to central necrosis, whereas the peripheral rim is due to the angioinvasive nature of lymphomatoid granulomatosis. ${ }^{14}$ Thus, a similar computed tomography (CT) appearance of the RHS may occur due to differing pathological processes. In angioinvasive fungal infections (and possibly in pulmonary thromboembolism), the central ground-glass opacity is due to infarct with preserved air spaces, whereas in organizing pneumonia, the central ground-glass opacity is due to inflammation of the alveolar septa alone. The rim of consolidation is due to dense inflammation, granulation tissue, or hemorrhage within the alveolar air spaces.

\section{Discussion}

The CT appearance of central ground-glass opacity within a ring- or crescent-shaped rim of consolidation (Fig. 


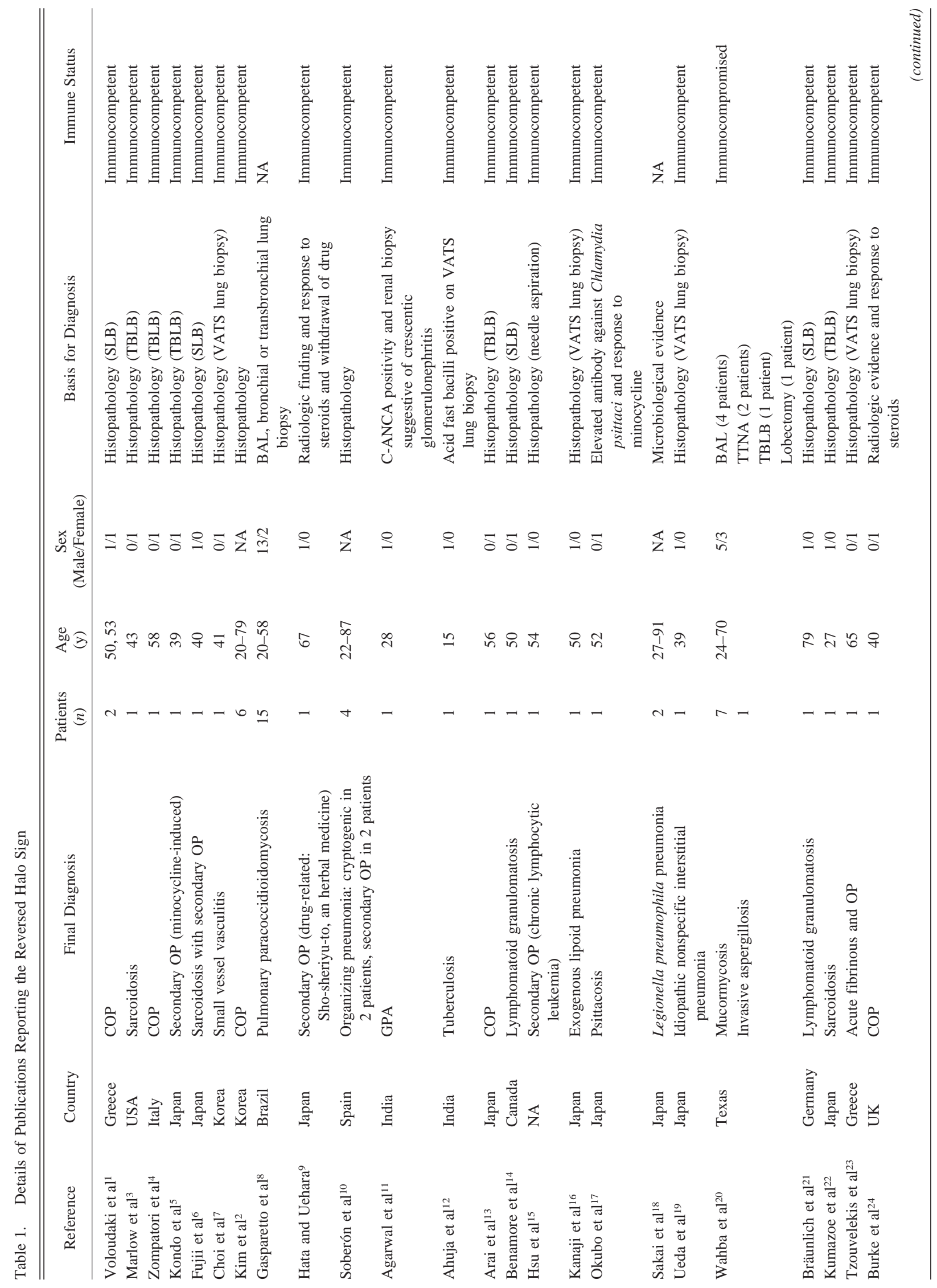




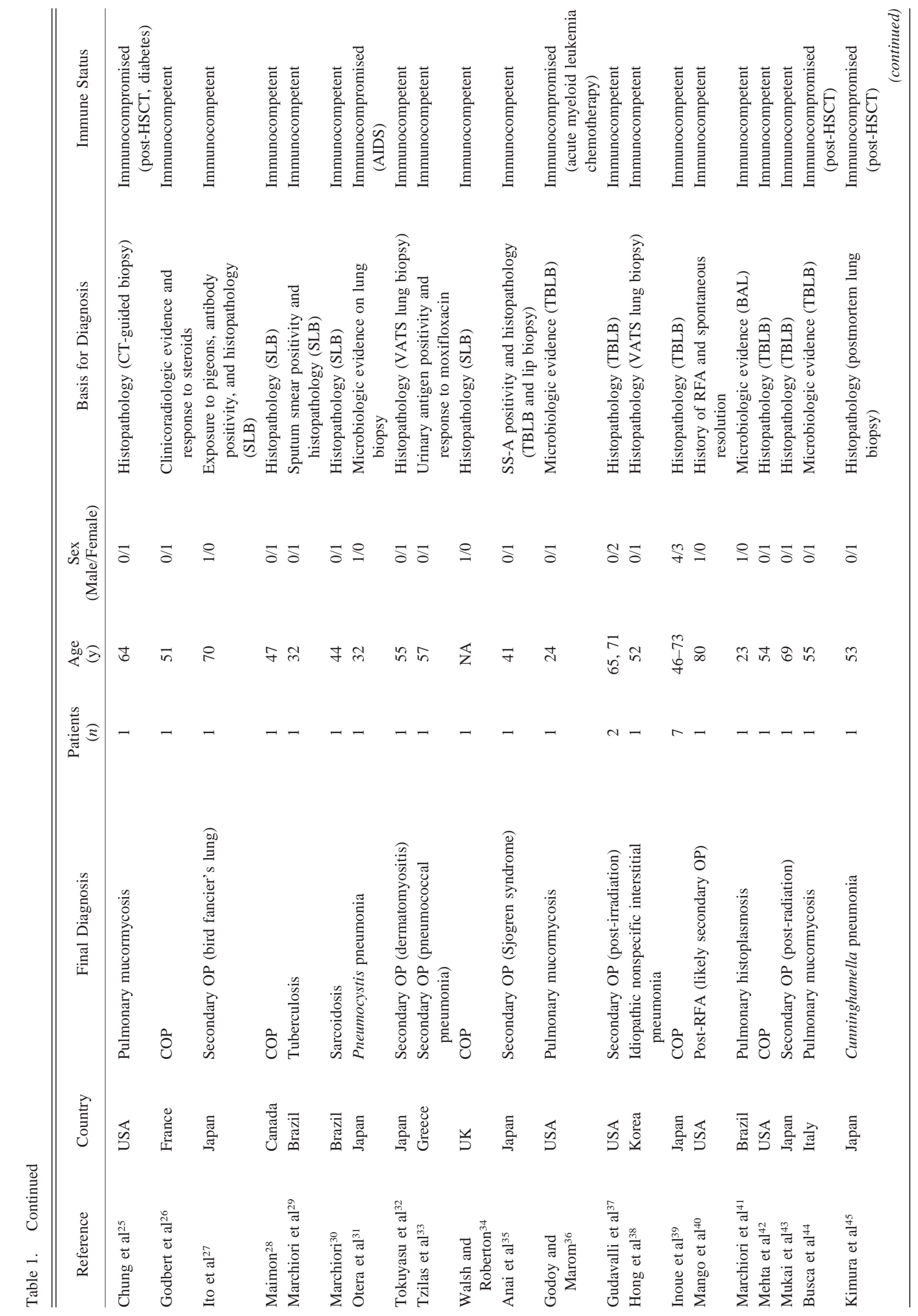


Reversed Halo SigN

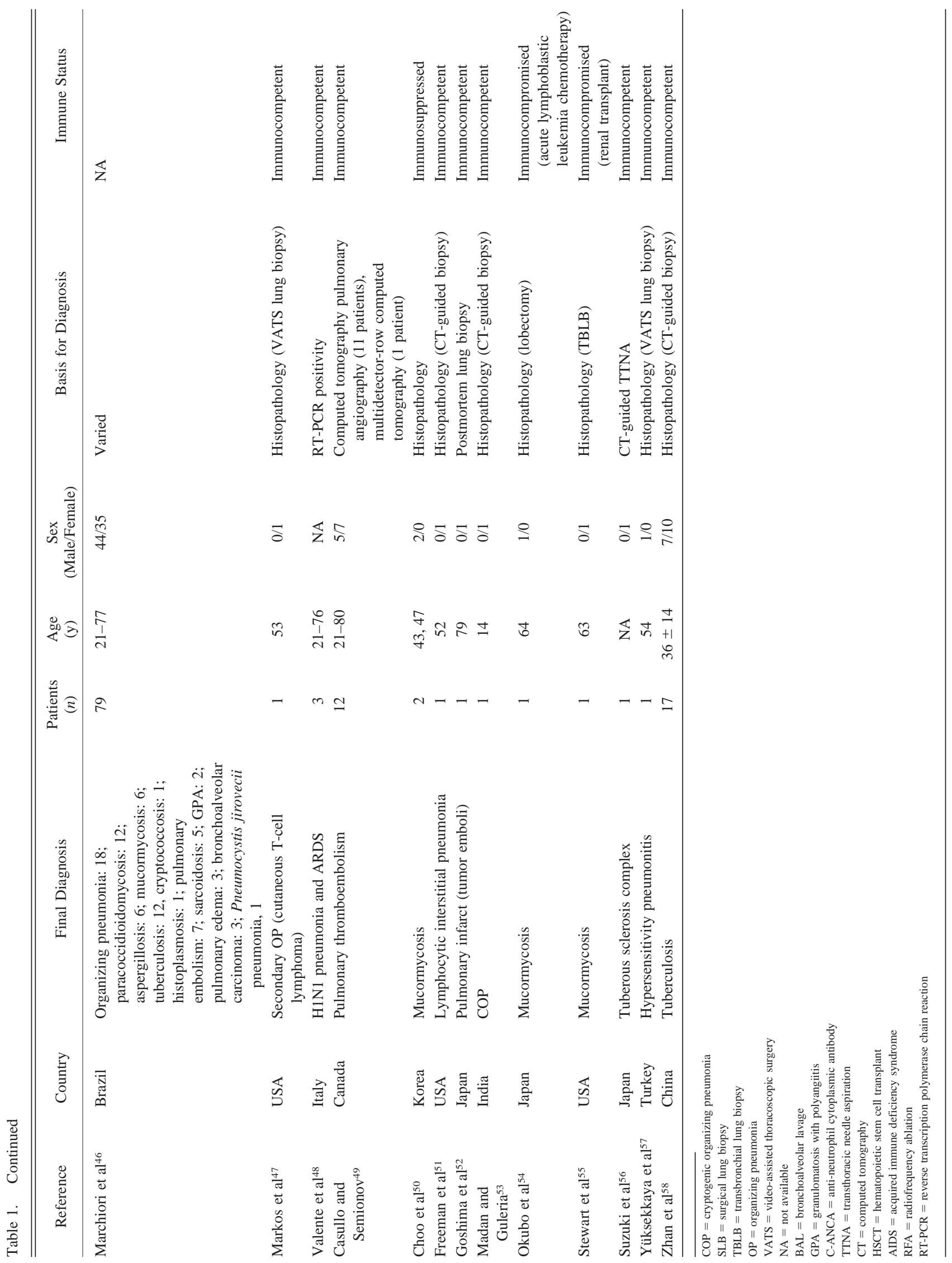


Table 2. Disorders Manifesting With the Reversed Halo Sign on Computed Tomography of the Chest

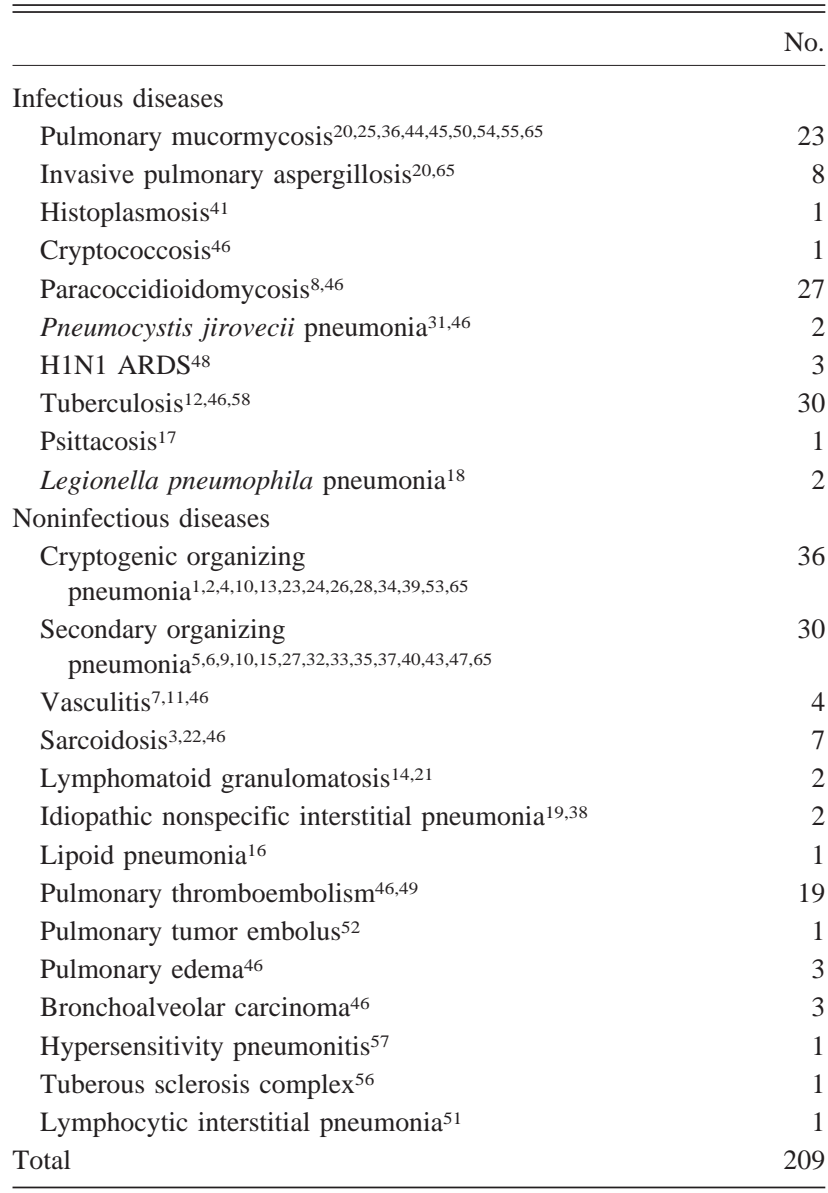

2) was first described by Voloudaki et $\mathrm{al}^{1}$ in two patients with cryptogenic organizing pneumonia. Similar descriptions of such ring or annular opacities were also provided by Kondo et $\mathrm{al}^{5}$ and Fujii et al, ${ }^{6}$ who described this pattern in patients with secondary organizing pneumonia. The term "reversed halo sign" was first used by Moon et al ${ }^{59}$ when they described four patients with cryptogenic organizing pneumonia with this radiologic sign. Subsequently, the same group compared the CT findings of 31 patients with biopsy-proven cryptogenic organizing pneumonia with 30 patients without cryptogenic organizing pneumonia. The RHS was noted in 6 patients with cryptogenic organizing pneumonia (19\%) and in none with other diseases. ${ }^{2}$ The authors concluded that the presence of the RHS is a specific radiologic finding of cryptogenic organizing pneumonia.

The RHS was initially defined by Kim et $\mathrm{al}^{2}$ as a central ground-glass opacity surrounded by a denser consolidation with a crescentic (forming more than three fourths of a circle) or ring (forming a complete circle) shape of at least $2 \mathrm{~mm}$ in thickness. This description was slightly modified by the Fleischner Society in $2008,{ }^{60}$ which describes the

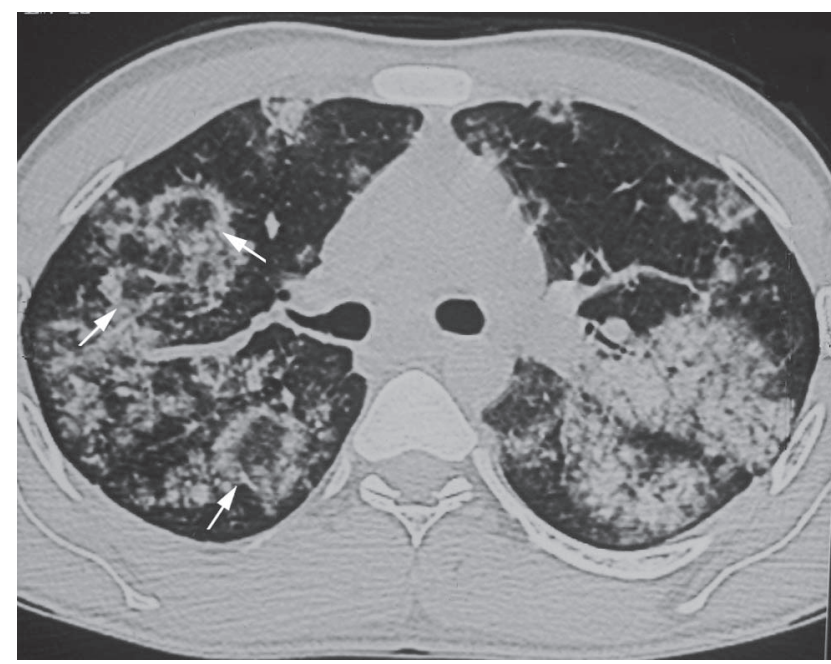

Fig. 2. High-resolution computed tomography of the chest wall showing multiple areas with the reversed halo sign (arrows).

RHS as a focal rounded area of ground-glass opacity surrounded by a more or less complete ring of consolidation. This CT appearance has been variously described by different authors as reversed halo sign, reverse halo sign, atoll sign, or fairy ring sign. Even before the term RHS was coined, Zompatori et $\mathrm{al}^{4}$ used the term "atoll sign" to describe the same CT finding in 1999. The word atoll is derived from atholhu, a Maldivian word meaning an island consisting of a lagoon surrounded by a circular coral reef.

In 1999, Marlow et $\mathrm{al}^{3}$ used the term "fairy ring sign" in a patient with sarcoidosis to describe a ring-shaped opacity with normal appearing lung parenchyma in the center. The term "fairy ring" is derived from Gaelic mythology. Fairies would dance in small circles at night, and when tired, they would rest on the toadstools. The next day, one would see only a circle in the grass with a ring of mushrooms, which is described as a fairy ring. In a strict sense, the fairy ring sign differs from the RHS in that the center of the ring is normal appearing lung parenchyma in the former and ground-glass opacity in the latter. However, some authors tend to use the terms interchangeably, as the difference between the two is only minor, and both signs are seen in the same diseases. On occasion, the same chest CT may show both the fairy ring sign and the RHS. ${ }^{34}$ As the terms atoll sign and fairy ring sign are not mentioned in the Fleischner glossary of radiologic terms, we suggest using the term RHS to describe this CT finding.

It was suggested previously that in an immunocompetent host, the presence of an RHS would be sufficient evidence for a trial of steroids and obviate the need for a lung biopsy. ${ }^{26}$ As shown in the systematic review, the RHS is associated with a number of diseases, both infectious and noninfectious. In fact, the presence of the RHS in an immunocompromised host should be attributed to invasive fungal infection unless proven otherwise. The RHS 


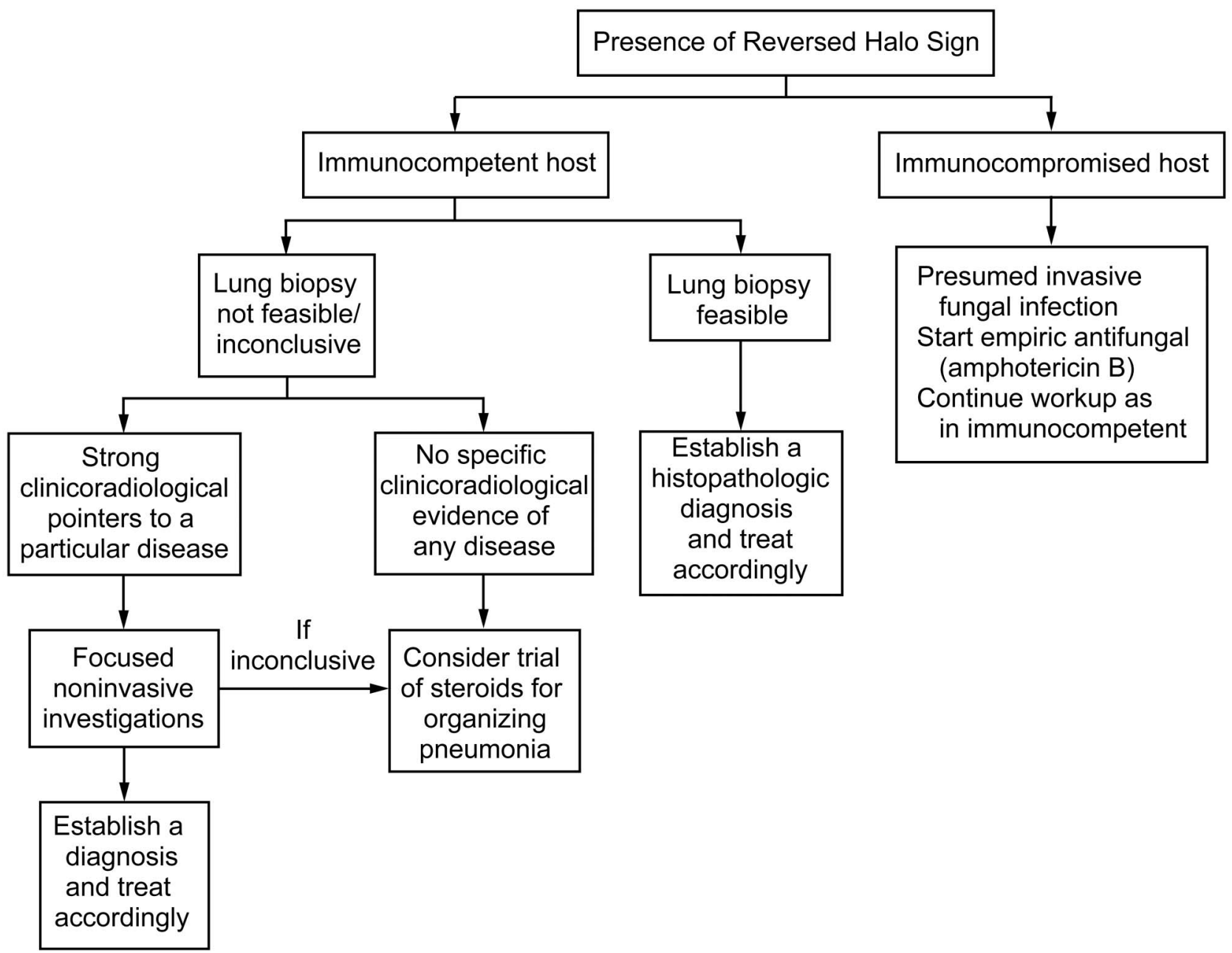

Fig. 3. Algorithmic approach for the reversed halo sign.

is also an early indicator of fungal infection, as it usually occurs within the first week of infection. ${ }^{61}$ In a study on sequential morphological changes in CT scan in pulmonary mucormycosis, it was shown that the halo sign and the RHS are the initial radiologic features. With treatment, they develop areas of central cavitation..$^{50}$ As opposed to the halo sign, which is more common with invasive aspergillosis, the RHS is most commonly seen with mucormycosis, and thus, its presence would indicate the need for a Mucor-specific antifungal agent such as amphotericin B or posaconazole. ${ }^{62}$ Also, it would be appropriate to rule out endemic infections such as paracoccidioidomycosis and tuberculosis depending on the patient's geographic location by appropriate investigations in patients presenting with RHS. To date, the RHS has not been described in typical community-acquired bacterial pneumonia, and hence, the presence of this sign should rule out a diagnosis of community-acquired pneumonia. With the growing number of diseases with which it is being associated, especially infectious causes, we would not recommend an empiric steroid trial (as proposed earlier) without an attempt made to confirm the diagnosis. ${ }^{26}$

Of the noninfectious causes of the RHS, the most commonly associated disease is organizing pneumonia. As the RHS can be encountered in both primary (cryptogenic organizing pneumonia) and secondary organizing pneumonia, it does not help in differentiating between cryptogenic and other causes. Thus, appropriate investigations should be carried out to rule out secondary causes (history of drugs, radiation exposure, connective tissue disease), which, if present, need to be treated simultaneously. Although many noninfectious diseases associated with the RHS (organizing pneumonia, hypersensitivity pneumonitis, sarcoidosis, vasculitis, cellular nonspecific interstitial pneumonia) might eventually need immunosuppression with steroids, it is important to confirm the diagnosis before starting therapy, as the degree and duration of immunosuppression needed in the individual disorders may vary. There are also reports of association with other rare diseases such as lipoid pneumonia, lymphomatoid granu- 
lomatosis, and bronchoalveolar carcinoma, further underscoring the need for a lung biopsy.

Marchiori et al ${ }^{63-65}$ have proposed several radiologic criteria to distinguish various diseases based upon the morphologic appearance of the RHS on the CT scan. They propose that the presence of nodular walls or nodules within the lesion indicates granulomatous diseases such as tuberculosis and sarcoidosis rather than organizing pneumonia. ${ }^{63,64}$ Similarly, a greater thickness of the rim $(>1 \mathrm{~cm})$, the presence of reticulation within the rim of consolidation, and the presence of an associated pleural effusion point toward a fungal pneumonia rather than organizing pneumonia. ${ }^{65}$

\section{Clinical Approach to a Case with RHS}

As the RHS is not specific for any disorder, we recommend an algorithmic approach as outlined in Figure 3. The overall clinical presentation needs to be considered while approaching a patient with RHS. In an immunocompromised host, amphotericin B should be initiated empirically for presumed invasive fungal infection, and further investigations should proceed depending on the clinical circumstances. In an immunocompetent host, we recommend lung biopsy wherever feasible before initiating treatment. Flexible bronchoscopy with bronchoalveolar lavage and lung biopsy should be the initial investigation, with CT-guided or surgical lung biopsy as alternative options. However, if a lung biopsy is not feasible, is contraindicated, or is inconclusive, focused noninvasive investigations should be performed as guided by the clinicoradiologic presentation of the patient to achieve a diagnosis. In countries endemic for tuberculosis or paracoccidioidomycosis, appropriate investigations have to be carried out to rule out these infections. Other investigations such as anti-neutrophil cytoplasmic antibody may be useful in the diagnosis of vasculitides. It is important to make a conclusive diagnosis before initiating treatment, as this sign is associated with both infectious and noninfectious diseases, for which the treatment approaches are totally differ. If lung biopsy and noninvasive investigations do not help in reaching a diagnosis, a trial of empiric steroids may be started once infections have been reasonably excluded.

Finally, our review is not without limitations. Although a systematic review, the data presented are a collection of case reports and case series, and hence, we cannot exclude publication and reporting biases.

\section{Conclusions}

The RHS, previously considered to be a hallmark of cryptogenic organizing pneumonia, can be encountered in a variety of pulmonary disorders, both infectious and noninfectious. The two most commonly associated diseases are the organizing pneumonias and invasive fungal pneumonias (especially mucormycosis). As the treatment approach for these two diseases is diametrically opposite, we recommend obtaining a tissue diagnosis whenever feasible. The clinical presentation, immune status of the patient, and associated radiologic findings can help in narrowing down the differential diagnosis. In an immunocompromised host, antifungal therapy for mucormycosis should be initiated pending further investigations.

\section{REFERENCES}

1. Voloudaki AE, Bouros DE, Froudarakis ME, Datseris GE, Apostolaki EG, Gourtsoyiannis NC. Crescentic and ring-shaped opacities. CT features in two cases of bronchiolitis obliterans organizing pneumonia (BOOP). Acta Radiol 1996;37(6):889-892.

2. Kim SJ, Lee KS, Ryu YH, Yoon YC, Choe KO, Kim TS, Sung KJ. Reversed halo sign on high-resolution CT of cryptogenic organizing pneumonia: diagnostic implications. AJR Am J Roentgenol 2003; 180(5):1251-1254.

3. Marlow TJ, Krapiva PI, Schabel SI, Judson MA. The "fairy ring": a new radiographic finding in sarcoidosis. Chest 1999;115(1):275-276.

4. Zompatori M, Poletti V, Battista G, Diegoli M. Bronchiolitis obliterans with organizing pneumonia (BOOP), presenting as a ringshaped opacity at HRCT (the atoll sign). A case report. Radiol Med 1999;97(4):308-310.

5. Kondo H, Fujita J, Inoue T, Horiuchi N, Nakao K, Iwata M, et al. [Minocycline-induced pneumonitis presenting as multiple ringshaped opacities on chest CT, pathologically diagnosed bronchiolitis obliterans organizing pneumonia (BOOP)]. Nihon Kokyuki Gakkai Zasshi 2001;39(3):215-219. Article in Japanese.

6. Fujii M, Ida M, Enomoto N, Nogimura H, Nakamura Y, Chida K, Nakamura H. [A case of sarcoidosis manifesting as annular opacities after multiple nodular shadows]. Nihon Kokyuki Gakkai Zasshi 2002; 40(12):970-974. Article in Japanese.

7. Choi YH, Im JG, Park CK. Notes from the 2001 Annual Meeting of the Korean Society of Thoracic Radiology. J Thorac Imaging 2002; 17(2):170-175.

8. Gasparetto EL, Escuissato DL, Davaus T, de Cerqueira EM, Souza AS Jr, Marchiori E, Müller NL. Reversed halo sign in pulmonary paracoccidioidomycosis. AJR Am J Roentgenol 2005;184(6):19321934.

9. Hata Y, Uehara H. [A case where herbal medicine sho-seiryu-to induced interstitial pneumonitis]. Nihon Kokyuki Gakkai Zasshi 2005; 43(1):23-31. Article in Japanese.

10. Bravo Soberón A, Torres Sánchez MI, García Río F, Sánchez Almaraz C, Parrón Pajares M, Pardo Rodríguez M. [High-resolution computed tomography patterns of organizing pneumonia]. Arch Bronconeumol 2006;42(8):413-416. Article in Spanish.

11. Agarwal R, Aggarwal AN, Gupta D. Another cause of reverse halo sign: Wegener's granulomatosis. Br J Radiol 2007;80(958):849-850.

12. Ahuja A, Gothi D, Joshi JM. A 15-year-old boy with "reversed halo". Indian J Chest Dis Allied Sci 2007;49:99-101.

13. Arai T, Inoue Y, Ando S, Inoue K, Tsuyuguchi K, Suzuki K, et al. [A case of cryptogenic organizing pneumonia showing reversed halo sign on computed tomography of the chest]. Nihon Kokyuki Gakkai Zasshi 2007;45(8):621-626. Article in Japanese.

14. Benamore RE, Weisbrod GL, Hwang DM, Bailey DJ, Pierre AF, Lazar NM, Maimon N. Reversed halo sign in lymphomatoid granulomatosis. Br J Radiol 2007;80(956):e162-e166. 


\section{Reversed Halo Sign}

15. Hsu A, Stark P, Friedman PJ. Focal organizing pneumonia with reversed halo sign. Appl Radiol 2007;36:8.

16. Kanaji N, Bandoh S, Nagamura N, Soo Chang S, Ishikawa S, Yokomise $\mathrm{H}$, et al. Lipoid pneumonia showing multiple pulmonary nodules and reversed halo sign. Respir Med Extra 2007;3(3):98-101.

17. Okubo T, Miyazaki E, Ueo M, Okubo F, Ando M, Fukami T, Kumamoto T. [A case of psittacosis with wandering infiltrates developing to acute respiratory distress syndrome]. Nihon Kokyuki Gakkai Zasshi 2007;45(5):419-423. Article in Japanese.

18. Sakai F, Tokuda H, Goto H, Tateda K, Johkoh T, Nakamura H, et al. Computed tomographic features of Legionella pneumophila pneumonia in 38 cases. J Comput Assist Tomogr 2007;31(1):125-131.

19. Ueda S, Inoue R, Tanaka K, Mizumori Y, Kawamura T, Nakahara Y, et al. [A case of nonspecific interstitial pneumonia with reversed halo sign on chest HRCT]. Nihon Kokyuki Gakkai Zasshi 2007;45(3): 248-252. Article in Japanese.

20. Wahba H, Truong MT, Lei X, Kontoyiannis DP, Marom EM. Reversed halo sign in invasive pulmonary fungal infections. Clin Infect Dis 2008;46(11):1733-1737.

21. Bräunlich J, Seyfarth HJ, Gessner C, Gradistanac T, Wirtz H. Lymphomatoid granulomatosis: a short description of an unusual case of the disease. Pneumologie 2009;63(12):697-701.

22. Kumazoe H, Matsunaga K, Nagata N, Komori M, Wakamatsu K, Kajiki A, et al. "Reversed halo sign" of high-resolution computed tomography in pulmonary sarcoidosis. J Thorac Imaging 2009;24(1): 66-68.

23. Tzouvelekis A, Koutsopoulos A, Oikonomou A, Froudarakis M, Zarogoulidis P, Steiropoulos P, et al. Acute fibrinous and organising pneumonia: a case report and review of the literature. J Med Case Rep 2009;3:74.

24. Burke L, Jacob BK. Reversed halo sign in cryptogenic organising pneumonia. BMJ Case Rep 2010. doi:10.1136/bcr.03.2010.2824

25. Chung JH, Godwin JD, Chien JW, Pipavath SJ. Case 160: pulmonary mucormycosis. Radiology 2010;256(2):667-670.

26. Godbert B, Clement-Duchêne C, Regent D, Martinet Y. [Do all cryptogenic organizing pneumonias require lung biopsy and steroid treatment?]. Rev Mal Respir 2010;27(5):509-514. Article in French.

27. Ito T, Sugino K, Satoh D, Muramatsu Y, Sano G, Sato K, et al. Bird fancier's lung which developed in a pigeon breeder presenting organizing pneumonia. Intern Med 2010;49(23):2605-2608.

28. Maimon N. A 47-year-old female with shortness of breath and "reversed halo sign". Eur Respir Rev 2010;19(115):83-85.

29. Marchiori E, Grando RD, Simões Dos Santos CE, Maffazzioli Santos Balzan L, Zanetti G, Mano CM, Gutierrez RS. Pulmonary tuberculosis associated with the reversed halo sign on high-resolution CT. Br J Radiol 2010;83(987):e58-60.

30. Marchiori E, Zanetti G, Mano CM, Hochhegger B, Irion KL. The reversed halo sign: another atypical manifestation of sarcoidosis. Korean J Radiol 2010;11(2):251-252.

31. Otera H, Tada K, Sakurai T, Hashimoto K, Ikeda A. Reversed halo sign in pneumocystis pneumonia: a case report. BMC Med Imaging 2010;10:26

32. Tokuyasu H, Isowa N, Shimizu E, Yamadori I. Reversed halo sign associated with dermatomyositis. Intern Med 2010;49(15):1677-1678.

33. Tzilas V, Bastas A, Provata A, Koti A, Tzouda V, Tsoukalas G. The "reversed halo" sign in pneumonococcal pneumonia: a review with a case report. Eur Rev Med Pharmacol Sci 2010;14(5):481-486.

34. Walsh SL, Roberton BJ. Images in thorax. The atoll sign. Thorax 2010;65(11):1029-1030.

35. Anai S, Kumazoe H, Wakamatsu K, Nagata N, Nakanishi Y, Kajiki A. [Reversed halo sign in organizing pneumonia secondary to Sjogren syndrome]. Nihon Kokyuki Gakkai Zasshi 2011;49(9):707-712. Article in Japanese.
36. Godoy MCB, Marom EM. Reversed halo sign in pulmonary zygomycosis. Thorax 2011;66(6):544.

37. Gudavalli R, Diaz-Guzman E, Arrossi AV, Chapman JT, Mehta AC. Fleeting alveolar infiltrates and reversed halo sign in patients with breast cancer treated with tangential beam irradiation. Chest 2011; 139(2):454-459.

38. Hong SH, Kang EY, Shin BK, Shim JJ. Reversed halo sign on thin-section CT in a patient with non-specific interstitial pneumonia. Br J Radiol 2011;84(1001):e103-e105.

39. Inoue Y, Yoshimura N, Shimada H, Saito H, Shimizu K, Kurata K, et al. [Clinical features of reversed halo sign in cryptogenic organizing pneumonia]. Nihon Kokyuki Gakkai Zasshi 2011;49(2):7580. Article in Japanese.

40. Mango VL, Naidich DP, Godoy MCB. Reversed halo sign after radiofrequency ablation of a lung nodule. J Thorac Imaging 2011; 26(4):W150-W152.

41. Marchiori E, Melo SM, Vianna FG, Melo BS, Melo SS, Zanetti G. Pulmonary histoplasmosis presenting with the reversed halo sign on high-resolution CT scan. Chest 2011;140(3):789-791.

42. Mehta H, Paoletti L, Pastis N, Judson M. Fairy ring sign on high resolution computed tomography in a patient with cryptogenic organizing pneumonia. Chest 2011;140(4):109A.

43. Mukai N, Tokuyasu H, Izumi H, Takeda K, Hikino H, Shimizu E. [A case of organizing pneumonia with a reversed halo sign following postoperative irradiation for breast cancer]. Nihon Kokyuki Gakkai Zasshi 2011;49(5):393-398. Article in Japanese.

44. Busca A, Limerutti G, Locatelli F, Barbui A, De Rosa FG, Falda M. The reversed halo sign as the initial radiographic sign of pulmonary zygomycosis. Infection 2012;40(1):77-80.

45. Kimura M, Araoka H, Uchida N, Ohno H, Miyazaki Y, Fujii T, et al. Cunninghamella bertholletiae pneumonia showing a reversed halo sign on chest computed tomography scan following cord blood transplantation. Med Mycol 2012;50(4):412-416.

46. Marchiori E, Zanetti G, Escuissato DL, Souza AS Jr., Meirelles GS, Fagundes J, et al. Reversed halo sign: high-resolution CT scan findings in 79 patients. Chest 2012;141(5):1260-1266.

47. Markos M, Takekoshi D, Joo M. Rare cresentic shaped radiographic findings of organizing pneumonia associated with cutaneous T-cell lymphoma. Chest 2012;142(4):554A.

48. Valente T, Lassandro F, Marino M, Squillante F, Aliperta M, Muto R. H1N1 pneumonia: our experience in 50 patients with a severe clinical course of novel swine-origin influenza A (H1N1) virus (SOIV). Radiol Med 2012;117(2):165-184.

49. Casullo J, Semionov A. Reversed halo sign in acute pulmonary embolism and infarction. Acta Radiol 2013;54(5):505-510.

50. Choo JY, Park CM, Lee HJ, Lee CH, Goo JM, Im JG. Sequential morphological changes in follow-up CT of pulmonary mucormycosis. Diagn Interv Radiol 2014:20(1);42-46.

51. Freeman MD, Grajo JR, Karamsadkar ND, Steffensen TS, Hazelton TR. Reversed halo sign on computed tomography as a presentation of lymphocytic interstitial pneumonia. J Radiol Case Rep 2013;7(10): 51-56.

52. Goshima H, Hiromi T, Nishio C, Fujii H, Katsuyama E. Reversed halo sign in pulmonary infarction with tumor emboli: a case report. Respir Invest 2013 [Epub ahead of print]. doi:10.1016/ j.resinv.2013.08.004.

53. Madan K, Guleria R. Reverse halo sign. Lung India 2013;30(1):7273.

54. Okubo Y, Ishiwatari T, Izumi H, Sato F, Aki K, Sasai D, et al. Pathophysiological implication of reversed CT halo sign in invasive pulmonary mucormycosis: a rare case report. Diagn Pathol 2013;8: 82.

55. Stewart JI, D’Alonzo GE, Ciccolella DE, Patel NB, Durra H, Clauss 


\section{Reversed Halo SigN}

HE. Reverse halo sign on chest imaging in a renal transplant recipient. Transpl Infect Dis 2014;16(1);115-118.

56. Suzuki K, Seyama K, Hayashi T, Yamashiro Y, Shiraishi A, Kuwatsuru R. Reversed halo sign in tuberous sclerosis complex. Case Rep Radiol 2013;2013:428501.

57. Yüksekkaya R, Çelikyay F, Yılmaz A, İnönü H, Köseoğlu D, Sade $\mathrm{R}$. Reversed halo sign in hypersensitivity pneumonia: a diagnostic difficulty. Respir Case Rep 2013;2(3):112-116.

58. Zhan X, Wang Z, Zhang L, Jin ML, Liu M, Chen WH, Dai HP. Clinical and pathological features of adult pulmonary tuberculosis with reversed halo sign. Int J Tuberc Lung Dis 2013;17(12):1621-1625.

59. Moon S, Ryu YH, Kim S, Choe KO, Lee J, Sung K. Reversed halo sign: a new supplementary CT finding in confident diagnosis of BOOP. Radiology 2000;217(S):335.

60. Hansell DM, Bankier AA, MacMahon H, McLoud TC, Müller NL, Remy J. Fleischner Society: glossary of terms for thoracic imaging. Radiology 2008;246(3):697-722.
61. Marom EM, Kontoyiannis DP. Imaging studies for diagnosing invasive fungal pneumonia in immunocompromised patients. Curr Opin Infect Dis 2011;24(4):309-314.

62. Georgiadou SP, Sipsas NV, Marom EM, Kontoyiannis DP. The diagnostic value of halo and reversed halo signs for invasive mold infections in compromised hosts. Clin Infect Dis 2011;52(9):1144-1155.

63. Marchiori E, Zanetti G, Irion KL, Nobre LF, Hochhegger B, Mançano AD, Escuissato DL. Reversed halo sign in active pulmonary tuberculosis: criteria for differentiation from cryptogenic organizing pneumonia. AJR Am J Roentgenol 2011;197(6):1324-1327.

64. Marchiori E, Zanetti G, Hochhegger B, Irion KL. Re: Reversed halo sign: nodular wall as criterion for differentiation between cryptogenic organizing pneumonia and active granulomatous diseases. Clin Radiol 2010;65(9):770-771.

65. Marchiori E, Marom EM, Zanetti G, Hochhegger B, Irion KL, Godoy MC. Reversed halo sign in invasive fungal infections: criteria for differentiation from organizing pneumonia. Chest 2012;142(6):1469-1473. 